\title{
An application of Arbitrage Pricing Theory on KSE-100 Index; A study from Pakistan (2000-2005)
}

\author{
${ }^{1}$ Anam Gul $\quad{ }^{2}$ Naeemullah Khan \\ [1]Foundation University of Engineering \& Management Sciences, Islamabad, Pakistan \\ [2] Assistant Lecturer, Foundation University of Engineering \& Management Sciences, Islamabad, Pakistan
}

\begin{abstract}
Arbitrage Pricing Theory takes into account more influencing factors other than the simple systematic risk, as defined in CAPM. In this study, we aim to evaluate stock returns using Arbitrage Pricing Model considering four macroeconomic factors i.e. Money supply, Interest Rate, Industrial Production and Foreign Exchange Rate. The prediction of stock returns is done by taking values of stocks of 37 companies from KSE 100 index on monthly intervals for the period 2000-2005. The results that came out for this study proved that APT does not prove to be effective in predicting stock prices in Pakistan.
\end{abstract}

Keywords: Arbitrage Pricing Theory, KSE 100 index, Pakistan

\section{Introduction}

Financial economists and investors have always been curious to derive models and theories which perfectly define the actual worth of any stock, at any period of time. Like the concept of Market Equilibrium, they supposed that if the demand of any stock increases, its price would also increase. But this is not the same case in actual world. Different set of factors determine the accurate price of any stock including macro and micro-economic variables.

Investors always have a meaningful motive behind investing their money i.e. to gain back their money in an amount which is more than the actual one. Markets are constantly changing; sometimes they go up and give you money on your investments and sometimes they go down as well; making you lose even at your last penny! Economists have been researching on the factors that are behind these ups and downs in the markets. One factor that they have been constantly researching on is Risk associated with the investments. Macroeconomic factors affect the returns, inculcating risk more or less inside the stock and therefore, affecting the actual \& expected returns.

In this study, we are focusing our research on the APT model which is a reformed and devised version of CAPM. Now one may think that why did a need arise among the researchers to refine CAPM when it was practically useful financial economic theory? The answer to these lies in the fact that despite the model's efficacy, it lacked in some dimensions as it lacked to explain the relationship among the stock and return. It stated that the rate of return and systematic risk are correlated, while the studies suggested that there are more factors attributing to the riskiness of the stock's rate of returns. In addition to this, there were many more implications regarding CAPM so financial economists started to work on devising a theory that was easy and had fewer assumptions as well as a theory which was vast in giving dimensions to investment risk. This fervent research gave rise to the Arbitrage Pricing Theory which was developed by Ross in 1976. It had the following assumptions:

1. Investors always give preference to more wealth than less wealth with obvious certainty

2. Capital markets are selling the homogeneous securities with perfect information i.e. they are Perfectly competitive

3. The random process of generating asset returns can be expressed as a linear function of asset of $K$ risk factors (or indexes).

$$
E\left(R_{i}\right)=\lambda_{0}+\lambda_{1} b_{i 1}+\lambda_{2} b_{i 2}+\ldots+\lambda_{k} b_{i k}
$$

Where;

$\square=$ the expected return on an asset with zero systematic risk

$\square 1=$ the risk premium related to the $j$ th common risk factor

$\boldsymbol{b} \boldsymbol{i j}=$ the pricing relationship between the risk premium and the asset; that is, how much responsive asset $i$ is to the $j$ th common factor. (Called factor betas or factor loadings)

By using this formula, we can calculate the expected returns on the assets invested. If the prices of the respective assets are not the same as expected from the calculations made by APT, then we assume that the investors will enter into arbitraging. This may involve "short-selling" of the assets to equalize the prices of the 
assets. Or investors may find some assets or a pool of assets (Portfolio) which may equal the risk of the mispriced assets resulting in generating an effective return.

There are limitations present in APT as there are no fixed factors that are well defined by Ross that affect the expected return of assets invested. They vary from one stock to another as different stocks have different sensitivities to the macroeconomic factors. But there are some factors that can be generalized as the macroeconomic factors affecting the expected rate of return on assets. These are as follows:

1. Money supply

2. Manufacturing Production

3. Shifts in interest rates

4. Foreign exchange rate

Significant research work has been done on APT keeping in view the above mentioned variables and others across the world and because of it; APT has proved to be fruitful in discovering the expected returns and then correlating it with the benefits of investing in such stocks.

\subsection{Research Objectives:}

As this theory is a good approximation for highly liquid stocks, we need to find out to what extent this model can be applied to stock market valuation in Pakistan. Also, keeping in view its vast application, we have an objective to determine the extent to which this theory can be used to evaluate the stock returns Pakistan, since prediction of the stock returns would be beneficial from the investor point of view. Moreover, determining affects of multiple macro-economic factors on stock return is another objective of our study. We are seeking to investigate whether volatility in macroeconomic factors do affect the stock prices or not. In addition to this, we are trying to determine whether arbitrage pricing model can be used as relevant tool to predict the security valuation of Pakistani stocks and how this procedural change benefits the investors in Pakistan and whether "riskless arbitrage" pays back the investor the actual price of a stock including profit.

Besides this we also seek to explore if there are more factors in Pakistan that affect the expected return of stock than just the systematic investment risk. These factor maybe other microeconomic factors that are caused generally by the organization itself. To conclude our research seek out to examine whether relationship exits between macroeconomic variables in Pakistan and the actual returns on stock and how APT model is used to estimate the expected risk premium of the security or a portfolio.

\subsection{Research Problem:}

"Whether APT determines the accurate expected returns of stocks in Pakistan"

\section{Literature Review}

When investors invest in certain type of share of stock, they expect to get a return on their money. Through valuation, they want to know how much return is expected on their stock. A process through which the present worth of a security is found out is known as valuation. (J.B Williams 1938). But on the other hand, the return cannot be solely predicted by valuating the stocks. The risk element must be considered too in it (Markowitz Portfolio selection Theory [1952-1956]). Significant researches have been done on APT ever since it was introduced by Ross (1976). Ingersoll (1984) stated that the one key advantage of APT is that it derives a simple linear pricing relationship with the factors affecting the asset prices, as opposed to some of the CAPM's assumptions that are questionable. Bruce N. Lehmann and David M. Modest (1985) examined the different strategies for forming portfolios, which significantly affect the unique factors affecting the risk premiums of the portfolios. The results came out to be very beneficial as this research proved that increasing the number of securities in the analysis can increase the performance of portfolios. Also, another conclusion they drew through this research was that 750 securities in a portfolio provided more markedly high performance as compared to a portfolio with 250 securities. Chen, Roll and Ross (CR\&R, 1986), examined the validity of the APT in the US securities market. They used US macroeconomic variables for the underlying risk factors driving stock returns. The results showed that many of the macroeconomic variables used for the study were important and helpful in explaining the expected return derived from stock, especially in industrial production, variations in risk premium, and the shifts in the yield curve. Equilibrium versions of APT were also given as the equilibrium APT models of Dybvig (1983), Grinblatt and Titman(1983), and Connor (1984). Another study by Louise M. Arthur, Colin A. Carter and Fay Abizadeh (1988) examined the relation between risk and returns for agricultural assets and concluded that APT is more efficient in explaining the returns for agricultural assets than CAPM. Puneet Hunda and Scott C. Linn (1993) tested APT when insufficient information is available on asset returns. The results indicated that factor betas found out through normality distribution methods underestimated the inadequate information available for the respective securities and overestimated for securities which give higher information which meant that the return residuals were correlated with absent information. They also came to 
light that by adding new securities in a sequence and estimating through linear factor model, additional priced factors come into light when they don't even exist but are significantly important. Lee Sarver, George C. Philippatos (1993) examined the spot foreign ecxchange risk premium using APT. They tested that the deviations in the returns of currency depend on measuring systematic risk. Numerous tests proved that the exchange returns can be explained by APT using a single-factor. Gregory Koutmos, Panayiotis Theodossiou (1993) tested the conditional heteroskedasticity with some factors using APT. The results were that heteroskedasticity can produce erroneous estimates of betas and these betas can lead to wrong conclusions and another conclusion they drew was that by putting together individual securities into a portfolio and forming their group as a portfolio does not completely erode the conditional heteroskedasticity present in it.

Numerous defenders like Sharpe (1964) and Cheng (1994) support CAPM while Chen et al (1994) and Fama and French $(1992,1993,1996)$ are the supporters of APT. There are some researchers too who are questioning the viability and implementation of both models, like Shanken (1986) and Dhrymes et al (1985).

Across the world, APT model has always been a center of attraction to determine different factors in the respective economies. Séverine Cauchie, Martin Hoesli, Dušan Isako (2002) conducted a research on Swiss market which is particularly famous for having an effect from foreign economic conditions on it. Using APT, they examined the monthly returns on 19 industrial sector portfolios from 1986 to 2002 using both statistical and macroeconomic models. The results revealed that statistically determined factors give us a better picture of the determinants of stock returns other than the macroeconomic variables. Also, they concluded that the stock returns are effected both by the local and the foreign economic conditions. Horst Entorf, Gösta Jamin (2003) performed a research for the determination of exposure to and pricing of exchange rate risk using APT modelling in the dollar and the German stock market. Another significant study was carried out on APT in Istanbul in which 13 macroeconomic variables were used including money supply, industrial production, crude oil prices, consumer price index etc. The Istanbul Stock Exchange's stocks were built on these factors which were drawn on 11 portfolios from the industry sector. The results were that there exists no relationship between the actual returns on the stock and the macroeconomic variables used in the research. (M.H.Ebrahimi Sarvolia , A.saleh Ardestani , J.Hajibozorgi , H.Ahmadinia, 2010) did research on portfolio management in an Investment Company in Tehran stock exchange (TSE) using CAPM, APT, Systematic and Unsystematic Risk indicators. They examined 12 firms since 21 March 2005 to 20 March 2009, selected from Tehran stock exchange and the results suggested that systematic \& unsystematic risk, CAPM \& APT should be observed all together in performing evaluation procedure of investment company's performances.

Changyou Sun and Daowei Zhang (2001) applied APT and CAPM both to examine the financial performance on eight forestry-related investments. Although CAPM provided significant results as compared to the previous research done on timberland investments, they found that the results concluded by APT were more robust and beneficial. APT has been constantly tested globally to test its validity in the stock markets of the world. Altay E. (2003) employed various economic variables which consider the basic indicator of an economy; from those economic variables, he derived the factor analysis process and factor realizations of principle economic phenomena for two countries Germany and Turkey. The idea behind employing macroeconomic variables is described to be just quantitative indicators of basic economic phenomena. He tested the period of January 1988 to June 2002 and January 1993 to 2002 for Turkey and Germany respectively. The tested macroeconomic variables are; consumer price index, wholesale price index, imports, exports, foreign exchange rate, average yield of public bonds, industrial production index, money market interest rate. For German stock market, he found the evidence of only one factor beta, unexpected interest rate level factor beta, reward in the market. For Turkey market, the result can not present evidence for statistically significant unexpected macroeconomic factor beta expected asset return relation for the Turkish stock exchange during the tested period. Raj Dhankar \& Rohini Singh (2005) conducted a research to estimate the factors that influence stock returns in India. Through analysis of the Indian stock market using monthly and weekly returns for 1991-2002, they concluded that APT with multiple factors provides a better indication of asset risk and estimates of required rate of return than CAPM which uses beta as the single measure of risk. Another study was conducted in Australia (Gaoxiang Wang, 2008) in which he studied that whether the macroeconomic variables defined through Arbitrage Pricing Theory (APT) can explain the returns on the stock indexes in Australia. This research was based on the returns of stocks listed on the Australian Stock Exchange (ASX) during the period from 31 March 2000 to 31 December 2007. The research concluded that industry indices' returns can only be explained by three to five of the thirteen macroeconomic variables selected in the research. Empirical results suggest that macroeconomic variables, used in an APT framework, can explain consumer discretionary, energy, financial, IT, and materials, price index returns, but cannot explain other index returns. Generally, APT is a desirable model in examining the ASX200, as it explains half of the industry indices' returns. A significant study was conducted by Turgut Türsoy, Nil Günsel \& Husam Rjoub (2008) in which they tested APT in the Istanbul Stock Exchange (ISE) from February 2001 to September 2005 monthly. They took 13 macroeconomic variables against 11 industry portfolios to analyze the effect of these variables on the returns of stocks. The results they 
concluded was that APT failed to explain relationship between macroeconomic variables and stock's returns.

Another important study was conducted in Indonesia (Erie Febrian, Aldrin Herwany, January 2010) in which the researchers wanted to investigate the ability of CAPM and APT in explaining the additional returns of portfolio of stocks traded in Jakarta Stock Exchange (JKSE). They used data from three important economic eras i.e. pre-crisis period (1992-1997), crisis period (1997-2001), and post-crisis period (2001-2007). The results came out in the favour of APT as it proved that Beta is not the only factor that can explain the portfolio's additional returns. APT has proven to be right in explaining the portfolio excess returns in the periods in which they observed i.e. they found out that excess return averages are found to be consistently negative. They also found out that risk-premiums vary over the observation periods in which the study was conducted. Unfortunately, no such research has been done until now to test the APT model on stocks here. Pakistan experiences great fluctuations in macroeconomic factors every now and then. So we must try to test the viability of APT in Pakistan being a crucial region through this research.

\subsection{Development of Hypothesis:}

\section{Research Hypothesis}

There are four major independent variables; Money Supply, Interest rate, Foreign Exchange Rate \& Industrial Production. The hypotheses are developed on the basis of these variables.

\section{Independent Variables: \\ - Industrial production \\ - Money supply \\ - Foreign Exchange rate \\ - Interest rate \\ Dependent variable: \\ - $\quad$ KSE market}

\subsection{Hypothesis:}

Following hypothesis is formulated for the research being carried out on stock returns in Pakistan using Arbitrage Pricing Theory;

$>\mathrm{H}-1=$ "The Arbitrage Pricing Theory explains the return of stocks in Pakistan"

$>\mathrm{H}-2=$ "The Arbitrage Pricing Theory does not explain the returns of stocks in Pakistan".
Independent Variables
Dependent Variable

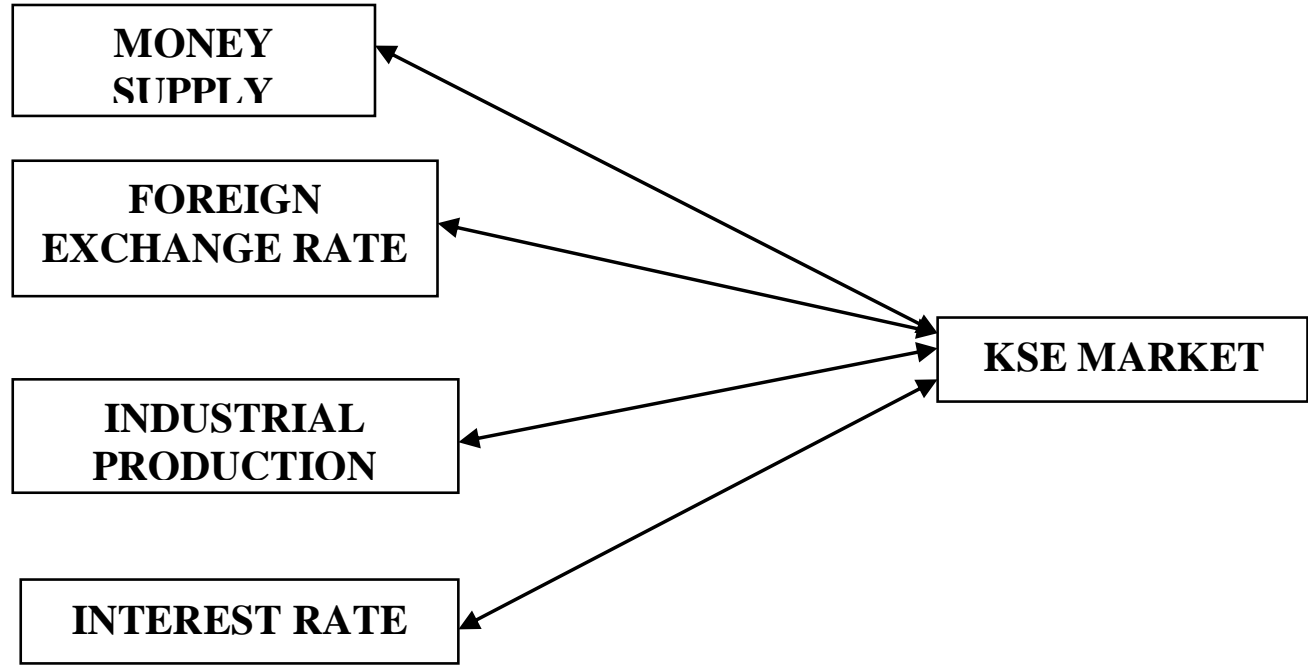

4.1 Methodology:

\section{RESEARCH DESIGN}

The APT itself does not provide specific guidance on the choice of macroeconomic factors, and the approach to the choice of factors has usually been to some extent arbitrary and controversial. The number of factors and factor loadings in the APT model are determined through Principal Component Analysis (PCA). The software used is SPSS 12.0 for windows and Eview 5.1. We report only the methodology used for the 5-year general 
case. The procedure contains three important stages; In the first stage we chose stocks of 36 companies of the KSE-100 index (Karachi Stock Exchange).

\section{Step 1:}

Returns of these stocks are taken using the following formula (using monthly data of the specified companies):

Stock Return $=\underline{\text { Closing stock price }- \text { Opening Stock Price }}$

Step 2:

Opening Stock Price

In the Second stage the economic variables returns are calculated using the following formula:

Money Supply Return (monthly) = Closing M2 rate - Opening M2 Rate

$$
\text { Opening } \mathrm{M} 2 \text { rate }
$$

The same formula was applied for the rest of the variables i.e. Industrial Production, Interest Rate and Foreign Exchange Rate.

After calculating the specific values of variables in the preceding step, betas are calculated by regressing the stock returns with the respective economic factors returns over the five years (2000-2004)

Step 3:

The factors lamdas are calculated by regressing the macroeconomic factor values with Risk Free Rate of Return (T-bills)

Step 4:

In this step, We calculate factor loadings by regressing the Betas calculated (from the stock returns) with the Lemdas (of the macroeconomic variables) calculated.

\section{Step 5:}

This step involves the third regression to test that whether our model predicts the validation of APT in Pakistani market or not. In this step, we passed a third regression test and regressed the stock returns of 37 companies with the factor loadings of each macroeconomic variable step by step.

This step basically involved the investigation to check that whether the constants come linear to each other when stock returns were taken as dependent variable and the factor loadings were interchanged. The constant of stock returns must come linear to that of the factors that are interchanged with each other to derive a constant that matches stock returns constant.

\subsection{Data Collection:}

- Source of data is FBR, SBP, KSE \& IMF.

- The observation period is from January 2000-2004 where we have predicted the stock values, and the prediction has been tested for the year 2005.

- All return data are calculated on a monthly interval.

\subsection{Sample:}

The sample we have selected for our research comprises of 37 companies:

\begin{tabular}{lllllll} 
AGTL & ENGRO SHEL & \multicolumn{2}{r}{ JOVC } & \multicolumn{2}{r}{ INDU } & DGKC \\
FABL & MARI & NRL & HUBCOSSGC & AGIC & \\
ABOT & GNP & GTYR & GADT & SNGP & PTC \\
CEPB & KOHE & FFLM & CASP & LUCK & SNBL \\
TRIPF & TELE & SAIF & AGIL & ICI & HCAR \\
IBFL & BIFO & BAHL & CHCC & AICL & DSFL \\
FFC & & & & & \\
\hline
\end{tabular}

\section{Results and Analysis}

T and significance:

These are the t-statistics and their associated 2-tailed p-values used in testing whether a given coefficient is significantly different from zero, using an alpha of 0.05 . (with reference to the Table 1 in Appendix)

\section{Market and manufacturing production}


The coefficient of manufacturing production is -1.466 ; this depicts that for every increasing unit of manufacturing production, -1.466 units decrease in market price is predicted, holding all other variables constant.

\section{T-test and significance:}

The coefficient of manufacturing production -1.466 is significantly different from 0 , because the p-value $(0.024)$ is smaller than 0.05 .

\section{Market and Money Supply}

The coefficient of money supply is -0.58 ; so for every increasing unit of money supply, -0.58 units decrease in market is predicted, holding all other variables constant.

\section{T-test and significance:}

The coefficient of manufacturing production -0.58 is not significantly different from 0 because the p-value is 0.203 which is larger than 0.05 .

\section{Market and foreign exchange}

The coefficient of foreign exchange is 0.167 , which tells us that with every one unit increase in foreign excange cause 0.167 units increase in market .

\section{T-test and significance:}

The cooefficient of foreign exchange 0.167 is significantly different from 0 because the p-value is 0.004 , which is less than 0.005 .

\section{Market and interest rate:}

The coefficient of interest rate is -0.679 telling us that with every one unit increase in interest rate will cause 0.679 decrease in market.

\section{T-test and significance:}

the coefficient of interest rate -0.679 is not significantly different from 0 because the p-value is 0.202 which is larger than 0.05 .

As the APT model says that for the effectiveness of the model, it is important for all variables to be significantly different, and hence prooved in the above calculations, that all variables togther do not satify the criteria. Due to which we can say that APT has not been able to proove itself worthful in depicting future prices of stocks in Pakistan.

\section{Conclusion \& Recommendations:}

Arbitrage Pricing Theory takes into account more than one factor to predict the expected returns of stocks. Unlike CAPM, which uses just the systematic risk to explain the returns; APT takes into account a variety of multifactors to explain the stock returns. To test APT in Pakistan, we took 37 companies and their respective stock prices from 2000-2005. The lemdas, betas and factor loading were calculated separately for the expected returns. But the results concluded that the constants between the factor loadings and the stock returns do not match with each other as it is important for them to be the same. This is because APT itself does not clarify as to which macro or micro factors have to be taken into account to predict the model but by choosing them on our own, we had to prove that the stock returns for the years 2000-2004 matched the impact of macroeconomic variables on them \& the respective prices of those stocks matched that of their sensitivity to the macrofactors employed in this model, which this study failed to prove.

This APT model consisted of employing four macroeconomic factors i.e. v Money supply, Industrial Production, Interest rates and Foreign exchange rate on the KSE market prices of 37 different companies. These companies were selected from KSE-100 Stock Index from the year 2000-2005 based on monthly returns. The evidence that came out from the calculations \& interpretations is that APT does not provide accurate results when applied on Pakistani market and this model cannot be used to predict the stock returns in Pakistan. This research focuses on determining that whether this APT model can be applied on Pakistani stocks or not and whether it gives accurate results to apply it further on mor stocks as well as more economic factors could be used in it.

The results from our study also conclude that maybe other significant macro or micro factors can be used to test the validity of APT on Pakistan's stock market. But keeping in view the macrofactors currently used in our study, this model cannot be used by investors to predict the stock returns in Pakistan. As we know that APT remains silent on which macrovariables to be used in APT model, so this is a limitation to our study as there are no well-defined variables on which to do research. CAPM can prove to be effective in this case as it employs the systematic risk or even by applying APT \& CAPM together on Pakistan's Stock market and increasing the time period of study, empirical results can be drawn. 


\title{
3. Tables \& Figures
}

\section{Table 1:}

\author{
b. Dependent Variable: market
}

\begin{tabular}{|c|c|c|c|c|c|}
\hline \multicolumn{6}{|c|}{ Coefficients $^{\Delta}$} \\
\hline \multirow[b]{2}{*}{ Madel } & \multicolumn{2}{|c|}{ Unstandardized Coefficients } & \multirow{2}{*}{$\begin{array}{c}\text { Standardized } \\
\text { Coefficients }\end{array}$} & \multirow[b]{2}{*}{$t$} & \multirow[b]{2}{*}{ Siq. } \\
\hline & $\mathrm{B}$ & Std. Error & & & \\
\hline (Constant) & .373 & .138 & & 2.701 & .011 \\
\hline manf & -1.466 & 616 & -.324 & -2.379 & .024 \\
\hline $\mathrm{m} 2$ & -.058 & .045 & -.162 & -1.299 & .203 \\
\hline fx & .167 & .054 & .420 & 3.081 & .004 \\
\hline int & -.679 & .521 & -.185 & -1.304 & .202 \\
\hline
\end{tabular}

\section{References}

[1] Altay, E., 2003. "The Effect of Macroeconomic Factors on Asset Returns: A Comparative Analysis of the German and the Turkish Stock Markets in an APT Framework”, Martin-Luther-Universität Halle, Betriebswirtschaftliche Diskussionsbeiträge, Nr. $48 / 2003$

[2] Biniv Maskay,2006. “Analyzing the Effect of Change in Money Supply on Stock Prices” The Park Place Economist, Volume $\mathrm{XV}$.

[3] Changyou Sun and Daowei Zhang, 2001. "Assessing the Financial performance of Forestry-related Investment Vehicles: Capital Asset Pricing Model vs. Arbitrage Pricing Theory", American Journal of Agricultural Economics, 83(3) pp. 617-628

[4] Chen, N., 1981. "Some Empirical Test of APT", Journal of Finance. Vol.38, pp 1393-1414.

[5] Chen, N., Roll, R and Ross, S., 1986. "Economic Forces and the Stock Market", Journal of Business. Vol.59, No3, pp. 383-403.

[6] Daniel Agyapong, Charles Adjasi,Simon K. Harvey, (2008) "Effect of exchange rate volatility on the Ghana stock exchange", African Journal of Accounting, Economics, Finance and Banking Research Vol. 3. No. 3. 2008.

[7] Dhrymes, P. J., Friend, I. and Gultekin, N. B., 1984. "A Critical Reexamination of the Empirical Evidence on the APT", Journal of Finance. Vol.39, No2, pp323-346

[8] Erie Febrian, Aldrin Herwany, January 2010. "CAPM and APT Validation Test Before, During, and After Financial Crisis in Emerging Market: Evidence from Indonesia”, The International Journal of Business \& Finance Research, Vol.10, No. 1.

[9] Gaoxiang Wang, 2008."Test of Macroeconomic Variables Through Arbitrage Pricing Theory in Different Industry Indices in the Australian Stock Market”, Working Paper Series

[10] Gregory Koutmos, Panayiotis Theodossiou, 1993. "APT With Observed Factors and Conditional Heteroskedasticity”, Managerial Finance Volume: 19 Issue: $3 / 4$

[11] Horst Entorf, Gösta Jamin, 2003. "The Dollar and the German Stock Market: Determination of Exposure to and Pricing of Exchange Rate Risk Using APT-modelling", Working Paper Series

[12] Jonathan E. Ingersoll, 1984. "Some results in the theory of Arbitrage Pricing", Journal of Finance, Vol.39, Issue 4, pp.1021-1039

[13] Lee Sarver, George C. Philippatos, 1993. "The Arbitrage Pricing Theory and Foreign Exchange Risk Premia", Managerial Finance, Volume: 19 Issue: $3 / 4$

[14] Lehmann, B. N., \& Modest, D. M. (1988). The empirical foundations of the arbitrage pricing theory. Journal of Financial Economics 21(1), 213-254.

[15] Louise M. Arthur, Colin A. Carter and Fay Abizadeh, 1988. "Arbitrage Pricing, Capital Asset Pricing, and Agricultural Assets", American Journal of Agricultural Economics

[16] Markowitz, H. (1952), "Portfolio Selection", The Journal of Finance, Vol. 7,No. 1, pp.77-91

[17] M.H.Ebrahimi Sarvolia , A.saleh Ardestani, J.Hajibozorgi , H.Ahmadinia, 2010. "A Study of Portfolio Management in Accepted Investment Company in Tehran stock exchange using of CAPM, APT, Systematic and Unsystematic Risk Indicators", Working Paper Series

[18] Puneet Hunda, Scott C. Linn, 1993. “Arbitrage Pricing and Estimation Risk", Journal of Financial and Quantitative Analysis, vol. 28, No. 1, pp. 81-100

[19] Raj Dhankar \& Rohini Singh, 2005. "Arbitrage Pricing Theory and Capital Asset Pricing Model - Evidence from the Indian Stock Market", Journal of Financial Management and Analysis, forthcoming

[20] Séverine CAUCHIE, Martin HOESLI, Dušan ISAKO, 2002. "The Determinants of stock returns in a small open economy", NCCR FINRISK project on "Financial Econometrics for Risk Management”. Working Paper Series No. 80

[21] Turgut Türsoy, Nil Günsel \& Husam Rjoub, 2008. "Macroeconomic Factors, the APT and the Istanbul Stock Market”, International Research Journal of Finance and Economics, Issue 22, pp. 50-56. 